\title{
Integration of Service Learning into a Manufacturing Engineering Course: A Case Study
}

\author{
Murat Tiryakioğlu* \\ Tara E. Maxwell \\ Christopher P. Bird \\ Bryan W. Dempsey \\ James A. Harbodin II \\ Justin R. Laughner \\ Timothy A. Skelton \\ Michael Wood \\ Arif Şirinterlikçi \\ Sushil Acharya \\ Robert Morris University \\ Department of Engineering \\ 6001 University Boulevard \\ Moon Township, PA 15108
}

\begin{abstract}
The implementation of a service learning project into a manufacturing engineering course at Robert Morris University is discussed within this paper. The project has entailed the analysis of the production system of a local company utilizing several tools available in the literature, as well as recommendations for improvement. This initial experience with service learning has produced invaluable lessons, which are discussed in the paper, along with the findings and results of the service learning project.
\end{abstract}

\section{INTRODUCTION}

Service learning is "a teaching and learning strategy that integrates meaningful community service with instruction and reflection to enrich the learning experience, teach civic responsibility, and strengthen communities" (Servicelearning.org, 2008). As in every discipline, service learning has drawn attention from engineering programs. Many engineering departments have incorporated service learning into their curricula by offering technical assistance programs to not only local non-profit organizations, but also local industries, especially in the form of university extension or faculty members acting as technical consultants or board members to nonprofit or community-based organizations. A growing component of service activities of engineering programs is getting engineering students actively engaged in real-life hands-on service activities.

When applied successfully, service learning in engineering can assist both the technical and social development of engineering students through effective practical and real-life experiences. The impact of service learning on engineering programs was assessed by Eyler and Giles (1999) who included 1500 students from 20 colleges and universities in their study. The authors

* Corresponding author

e-mail: tiryakioglu@,rmu.edu 
determined that service learning had a positive impact on development of engineering students. Moreover, engineering students who engaged in service learning activities developed (i) greater tolerance for diversity, (ii) better personal and interpersonal skills, and (iii) helped achieving improved community and college relations. Students involved in these activities were found to work harder, be more curious, and connect learning to their personal experience, in addition to gaining a stronger understanding of the subject matter. Similar results were obtained by Astin et al. (2000) who analyzed the development of approximately 22,000 engineering students exposed to service learning. The authors reported major gains in academic performance, values, selfefficacy, leadership skills as well as their plans to participate in service activities after graduation. Recently, Oakes (2002), Thompson et al., (2005), Jawaharlal et al. (2006) and Duffy et al. (2008) provided examples of successful integration of service learning activities in engineering programs to help the community.

The literature on service learning in engineering addresses the efforts of academia to help mostly non-profit organizations and communities. Collaborations with industry in on-site projects have received less attention. This study outlines the introduction of a service learning component into a manufacturing engineering course that incorporated assistance to a local company. This was the first time service learning activity was used in an engineering course at Robert Morris University outside the program's capstone course, ENGR 4950 - Integrated Engineering Design. The overall experience is discussed here and lessons learned in this exercise are presented as well.

\section{SERVICE LEARNINg In AN INTRODUCTORY MANUfACTURING ENGINEERING CoURSE}

The ENGR 3610 - Fundamentals of Manufacturing Engineering course was selected to achieve major service learning experience in the Department of Engineering at Robert Morris University. The main objective of the course was defined as "introducing students to the role and function of the manufacturing engineer in the context of the production, inspection, quality control, and enterprise environments". Students enrolled in this course, mainly juniors, were asked to analyze the efficiency of the production system of a local plant, at the request of the chief operating officer (COO) of the company. Because the request was made before the start of the semester, the sequence of topics and early laboratory experiences were designed to prepare the students for this service learning component. The concepts of value adding processes, manufacturing competitiveness, lean manufacturing as well as production system assessment techniques such as value stream maps and other analytical techniques were addressed.

\section{Site Visit}

The initial site visit to the local company was planned in advance on a day at which all processes and lines that the product goes through were expected to be running. The plant layout drawings and a video of the production system were obtained at the initial site visit. These helped prepare the students for possible future visits so that all data could be collected within the time constraints. Through extensive communication with the company, issues such as nondisclosure agreements and rules set by the labor union were addressed.

The initial site visit started with a presentation by the company $\mathrm{COO}$ about the product and what kind of issues the company is facing with its manufacturing system. Then the students were taken where the raw material inventory is kept and they followed the production flow up to 
the point of shipment. During the site visit, each student took pictures of various parts of the plant. Moreover, the students counted all raw material and work-in-process (WIP) inventory on the shop floor. They also had informal interviews with the shop floor personnel and supervisors, who shared critical information, such as defect rates, which was used later in the simulations.

The site visit ended with an exit interview during which several issues that the students identified and took pictures of were shared with the company COO, who was not aware of them. Each student was given an opportunity to share his/her observations before the meeting was adjourned.

Additional site-visits were planned by students to obtain additional data and give a presentation on the results of this service learning acitivity. However, most of the communications handled remotely other than the presentation visit.

\section{The Current State of the Production System}

By using the data collected during site visits, students analyzed the current state of production by (i) a part flow map, (ii) a value stream map and (iii) the Best-Worst-Practical Worst Case (B-WPWC) method developed by Hopp and Spearman (2001). Performance measures relating to the current status of the production system is given in Table I.

The map of part flow on the factory floor, as determined by the observations made by the students, is presented in Figure 1. The hollow rectangles represent process lines, and dark rectangles represent locations of inventory storage, both raw materials and WIP. Note that there is WIP storage between all processes. Moreover WIP is held at two different locations between processes 2 and 3.

TABLE I

THE CURRENT STATUS OF THE PRODUCTION SYSTEM

\begin{tabular}{|c|c|}
\hline Raw Material Inventory & 68,760 parts \\
\hline Finished Goods Inventory & 4,538 parts \\
\hline Cycle Time & $1,052,995$ seconds \\
\hline Bottleneck Rate & 0.025 parts/second \\
\hline Raw Process Time & 2,735 seconds \\
\hline Current WIP & 104,799 parts \\
\hline Critical WIP & 276 parts \\
\hline Practical WIP & 844 parts \\
\hline
\end{tabular}

The value stream map for the product investigated by the students is presented in Figure 2, which provides details about the cycle time $(\mathrm{CT})$, change-over time $(\mathrm{CO})$, throughput rate $(\mathrm{TH})$ and value-added time (VA). Note that the total value-added time for this product is only 0.5 hours whereas the total production lead time is 368 hours. Therefore the ratio of total processing and wait time to value-added time is 736:1. In other words, value is added to the product during only $0.14 \%$ of the time that a part spends on the factory floor. It should be noted that a major part of the wait time takes place between processes 1 and 2, and processes 4 and 5 (219 hours).

Hopp and Spearman developed this technique to analyze whether the throughput rate and the WIP inventory levels are reasonable. The Best Case is achieved when throughput rate is equal to 
the production rate at the bottleneck. There is a critical WIP level necessary to achieve the Best Case. The Worst Case represents the system in which all WIP is processed at a workstation before they are moved to the next process. Therefore the lot size in this case is equal to the current WIP level. Practical Worst Case is an intermediate level which is determined by the level of WIP.

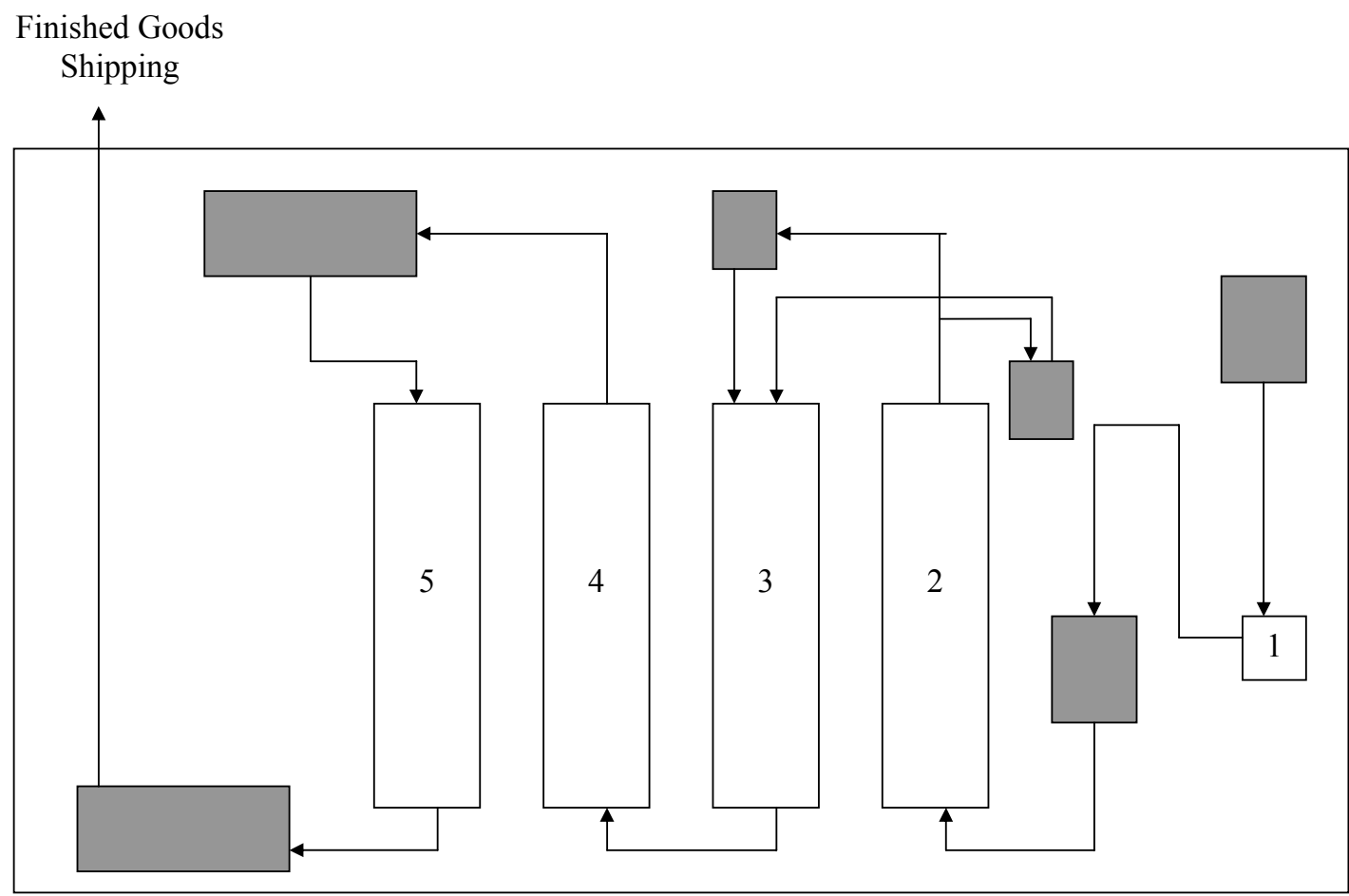

\section{FIGURE 1}

THE PART FLOW OBSERVED ON FACTORY FLOW. THE BOXES IN GRAY REPRESENT INVENTORY HOLDING LOCATIONS.

At the plant visited, it was determined that the throughput of the system is equal to the production rate of the bottleneck, Process 5. Because the bottleneck is at the end of the process flow, the production system is working at the Best Case level. However the current WIP level is significantly higher than the critical WIP necessary to achieve the Best Case level, as presented in Table I. Note that the current cycle time is $1,052,995$ seconds ( 292 hours) which is 385 times the raw process time. The current WIP level is 380 times the critical WIP level necessary to maintain the throughput rate at the current level. If the current batch levels are kept the same, the critical WIP level is 211 parts which is $0.8 \%$ of the current WIP. Hence the students determined that WIP level can be reduced significantly without sacrificing from the production output. 


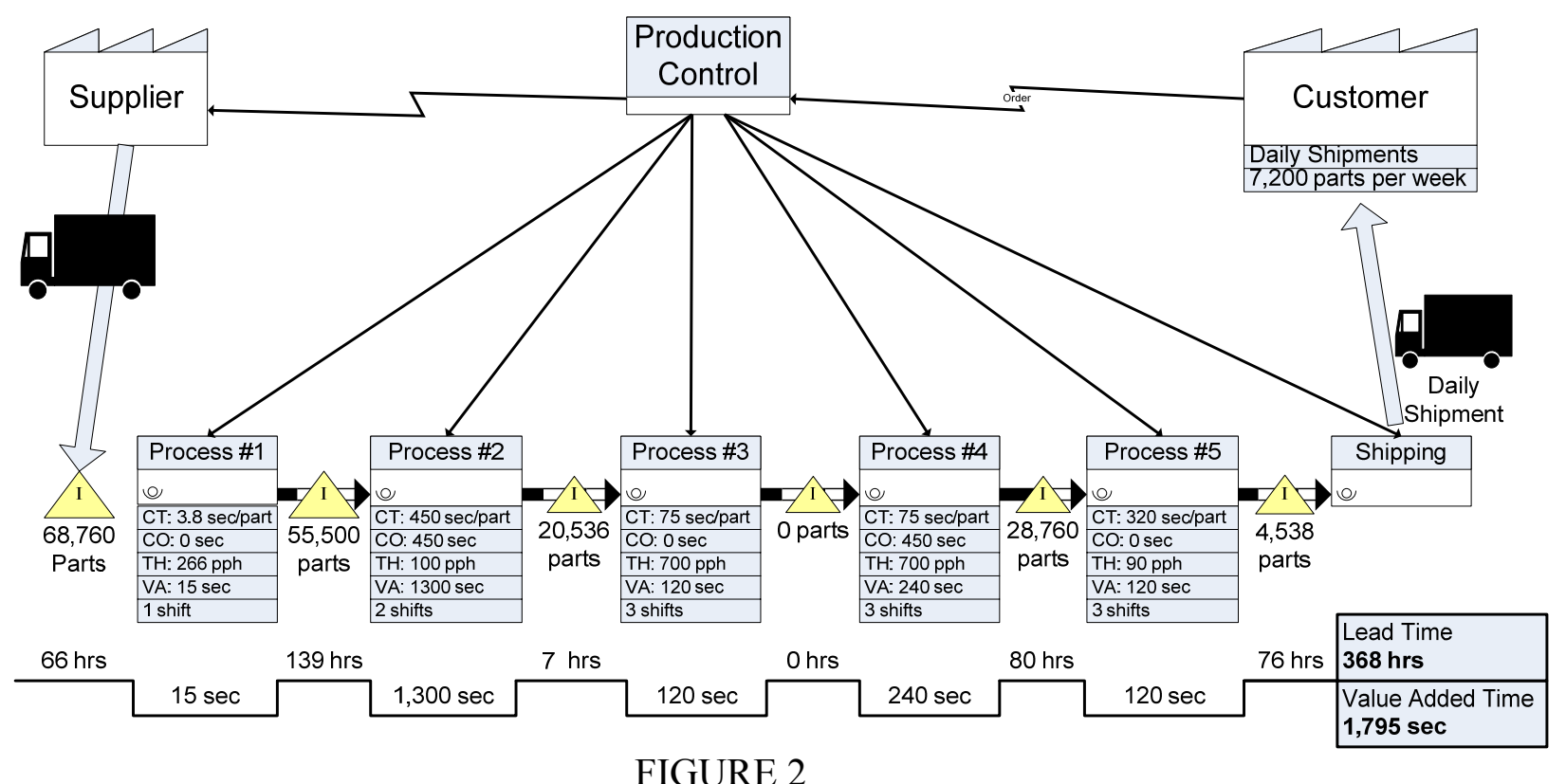

FIGURE 2

THE VALUE STREAM MAP OF THE PRODUCT FLOW OBSERVED ON THE FACTORY FLOOR.

\section{Recommendations Made for Improvement}

After extensive discussion and brainstorming, the following changes in the production system were recommended to the company COO:

1. Move Process 1 right before Process 2 so that WIP can be eliminated. Consequently, parts will come straight off Process 1 and be fed to Process 2. Since Process 1 operates much faster than Process 2, operation and loading can be done by the same operator.

2. Turn Process 2 line around so that its end is adjacent to Process 3.

3. Eliminate the clean room which does not add any value. Moreover, there is a high risk for damage to the parts, as witnessed during the visits. It was also observed that it was almost impossible to keep the dust out of the clean room, creating a potential for contamination and defects forming downstream.

4. Move Process 3 into the space currently occupied by the clean room. This proposed change requires less equipment. The excess equipment can be used elsewhere in the plant.

After these changes, the part flow in the plant is expected to be much smoother, as shown in Figure 3. The recommended changes in the production system will not only result in significant decrease in damage to the parts and eliminate root causes for certain defects, but also result in significant reductions in the WIP level. This is demonstrated in the expected value stream of the recommended system, presented in Figure 4. The production lead time is reduced by more than $60 \%$ and it is possible to reduce it even further by lowering the raw materials inventory. The recommended revisions eliminate many unnecessary steps that do not add value, such as loading and unloading into boxes and racks of the WIP storage.

The elimination of the "clean room" is expected to increase productivity significantly. The complex layout of the clean room and the associated material handling equipment generate significant risks for part damage. It is also essential that the clean parts be minimally exposed to 
dust, a task almost impossible to accomplish with the current layout. The recommended revisions in the layout minimizes, if not eliminates the risks of part damage and contamination.

\section{Flow Simulation for Current and Recommended Layouts}

Arena Simulation software, version 12.0, (by Rockwell Inc.) was used to perform a discrete event simulation of the processes in this project. The software was used to assess the current system as a baseline when comparing it to the performance of the recommended system, Figure 3. Entities were provided to the resources only when the resources were idle. The resources processed the entities in their inventory when no parts arrive from the upstream processes. This approach allowed the testing of the possible effect of defect rates on productivity gains achieved by the recommended improvements. In all cases, the run time for the Arena model was 7 days.

Simulation results demonstrated that the recommended changes in the production system would indeed increase productivity significantly, regardless of the defective rate level. Hence sufficient evidence was gathered about the robustness of the recommended production system.

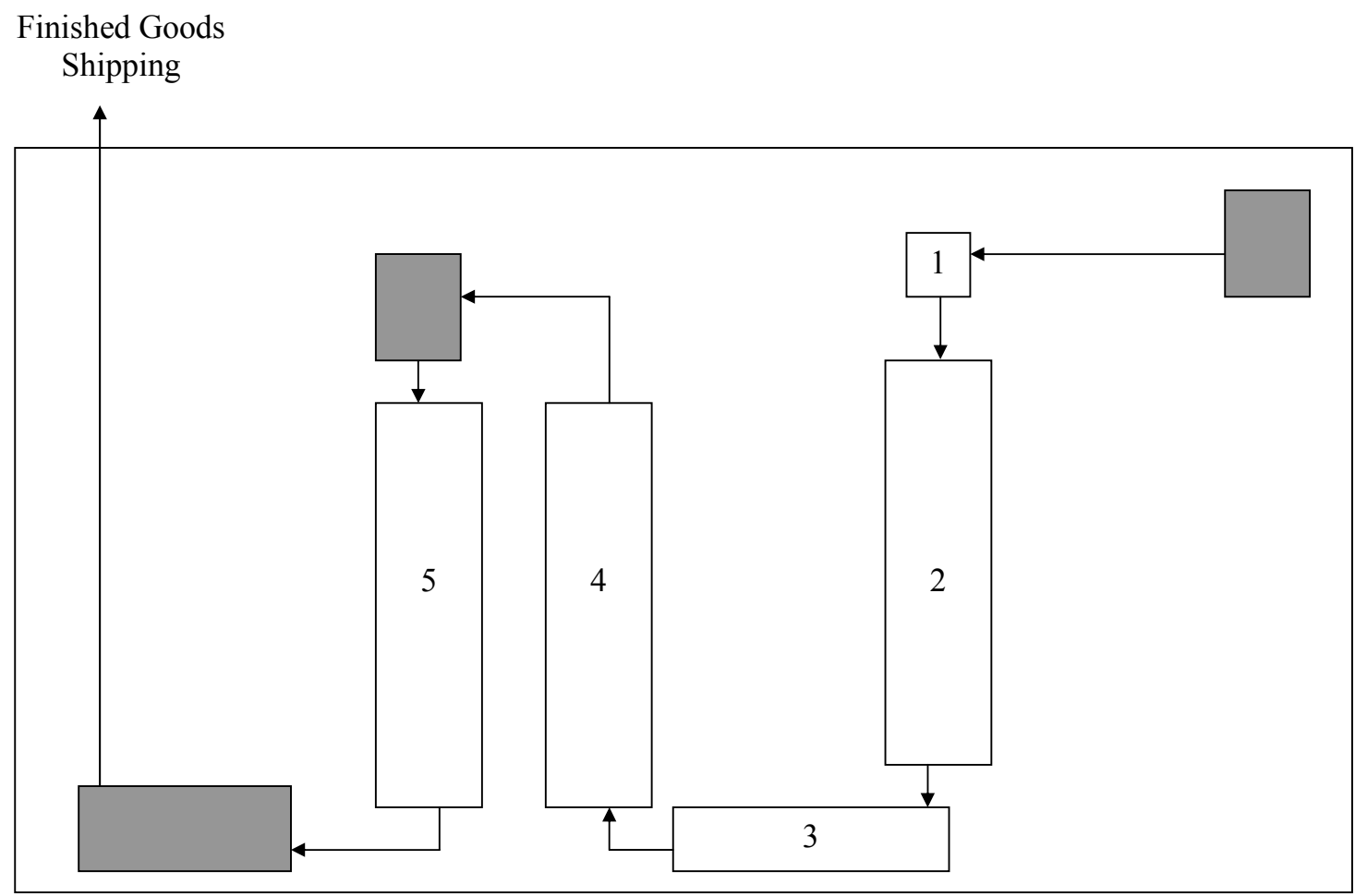

\section{FIGURE 3}

THE PART FLOW AFTER THE RECOMMENDED CHANGES TO THE MANUFACTURING SYSTEM. THE BOXES IN GRAY REPRESENT INVENTORY HOLDING LOCATIONS.

\section{Learning Outcomes from the Project}

To assess the learning outcomes of the service learning project, the students were given a survey, which is the modified version of the one developed by Baird (1998). The students were asked to rate each statement between 1 (strongly disagree) to 5 (strongly agree). The statements in the 
survey and the average response for each statement are presented in Table II. These results show that the students thought that the service learning experience not only helped them develop in personal and interpersonal areas, but also gave them a strong academic experience. The students seem to have benefited most from the time that they spent on site and interactions that they had with the industry. The results of the survey are consistent with the increased level of enthusiasm and motivation observed among the students during the project. Based on the success of this project, as evidenced by the outcomes listed in Table II, several service learning projects with industry were implemented in other Manufacturing Engineering courses at Robert Morris University.

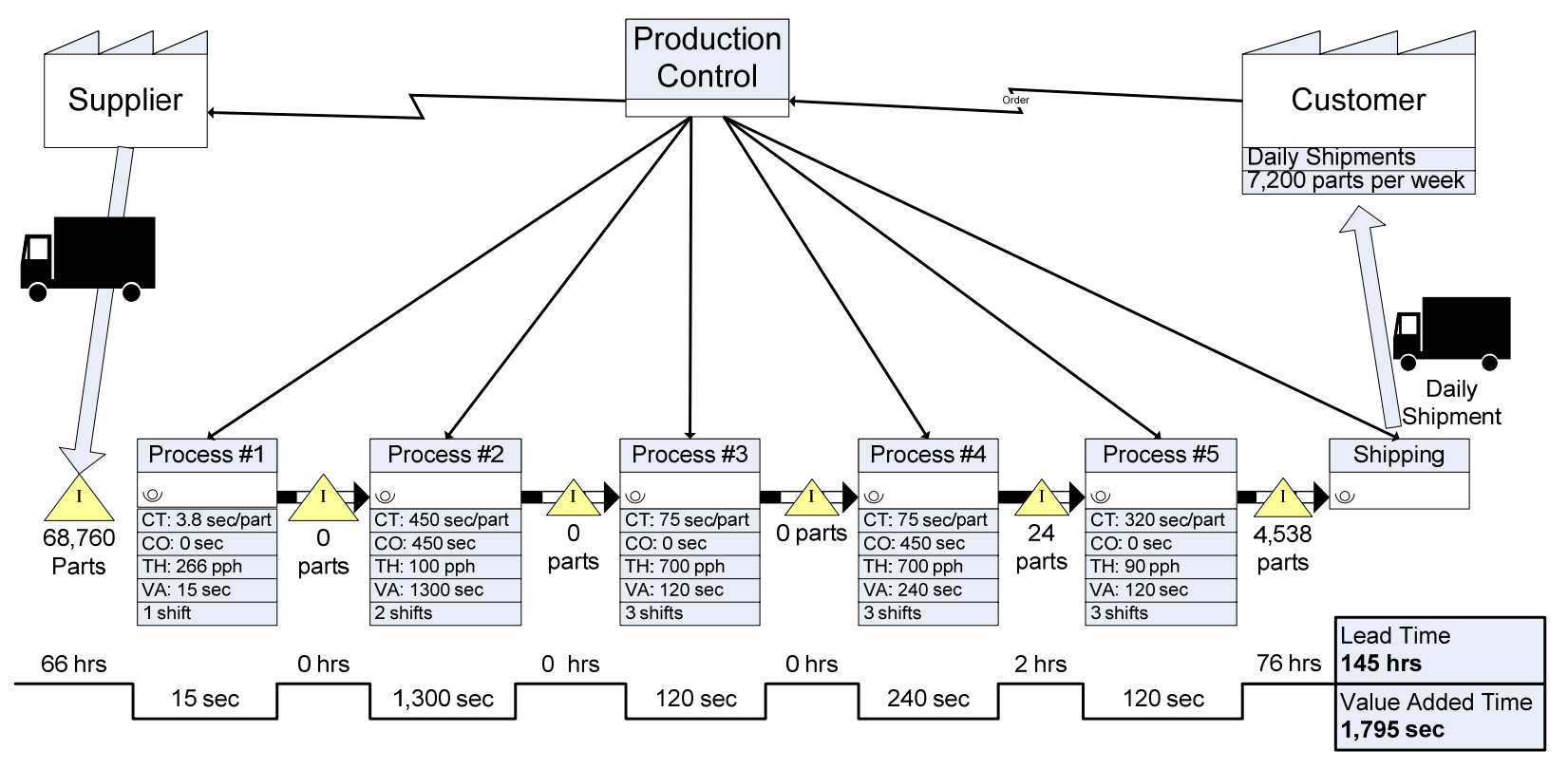

FIGURE 4

THE VALUE STREAM MAP AFTER RECOMMENDED CHANGES. 
TABLE II

THE RESULTS OF THE SURVEY CONDUCTED TO ASSESS THE PROJECT

\begin{tabular}{|l|r|}
\hline Personal & 4.6 \\
\hline Sense of usefulness, of satisfaction in doing something worthwhile & 4.2 \\
\hline Personal power, belief in ability to make a difference & 4.7 \\
\hline Openness to new experiences, to take risks and accept challenge & 4.6 \\
\hline Capacity to be productive, to persevere in difficult tasks & 4.4 \\
\hline Insight into your personal strengths and challenges & 4.1 \\
\hline Sense of personal achievement & 4.2 \\
\hline Sense of purpose or direction in life/profession & \\
\hline Interpersonal & 4.1 \\
\hline Concern for the welfare of others & 4.6 \\
\hline Ability to work cooperatively with others & 4.4 \\
\hline Ability to communicate effectively (listen and articulate ideas) & 4.4 \\
\hline Heightened leadership skills & \\
\hline Academic & 4.7 \\
\hline The project helped me understand the subject matter better & 4.9 \\
\hline $\begin{array}{l}\text { The onsite work and interaction with industry helped me understand } \\
\text { my profession better }\end{array}$ & 4.4 \\
\hline $\begin{array}{l}\text { I could not have learned the subject matter just as well (or better) by } \\
\text { traditional laboratory experiences on campus than by this service } \\
\text { learning project. }\end{array}$ & \\
\hline
\end{tabular}

\section{EPILOGUE}

One recommendation made by the students in this study was adopted immediately by the company. Other recommendations, however, were discussed extensively by the company executives. The inherent inefficiencies exposed in this study, along with expected need for floor space due to future lines, led the company to start the construction of a new production facility.

Although the project was regarded as a success by both the company administration and students, these important lessons were learned and implemented in other engineering courses with a service learning component:

- Early contact between company representative(s) and students is desirable to make the students more familiar with the project leader at the company (the COO in this case).

- A preliminary visit very early in the semester is important for the students to relate the course material to the service learning project requirements. 
- A second (backup) point of contact at the company is necessary to keep the project moving when the primary contact is unavailable.

- It is better to give the final report and presentation on campus rather than at the company site where there can be many distractions.

These lessons learned have been implemented in a Quality Engineering (ENGR 3680) course in which 3 service-learning projects for another local company were completed at relatively higher efficiency than this initial effort.

\section{REFERENCES}

Alexander Astin, Lori J. Vogelsang, Elaine K. Ikeda, Jennifer A. Yee, "How service learning affects students," (Los Angeles: UCLA Higher Education Research Institute, 2000), 2. Retrieved October 19, 2008 from http://www.gseis.ucla.edu/heri/PDFs/rhowas.pdf

Barbara Baird, "Rationale for Measuring Multiple Domains When Conducting Service-Learning Student Evaluation", In: Assessing Internal and External Outcomes of Service-Learning Collaborations, Eds.: Terry Pickeral and Karen Peters, 1998.

John Duffy, William Moeller, David Kazmer, Vivian Crespo, Linda Barrington, Carol Barry, David West, "Service-Learning Projects in Core Undergraduate Engineering Courses," International Journal for Service Learning in Engineering, 3, no.2 (2008), 18-41.

Retrieved October 19, 2008 from http://www.engr.psu.edu/IJSLE/home.htm

Janet Eyler, Dwight E. Giles, Where's the learning in service-learning?, (San Francisco: Jossey-Bass, 1999).

Valerie Hawks, Michael Miles, "Technology, Culture and the Manufacturing Engineer: How Studying SME's in Cambodia Can Teach Manufacturing Students About Global Enterprise," Proceedings of the American Society for Engineering Education Annual Conference, 2006, 1-8.

Wallace Hopp, Mark Spearman, Factory Physics $2^{\text {nd }}$ edition, (Columbus, OH: McGraw-Hill/Irwin, 2001).

Mariappan Jawaharlal, Uei-Jiun Fan, Saeed Monemi, "Implementing Service Learning in Engineering Curriculum," Proceedings of the American Society for Engineering Education Annual Conference, 2006, $1-11$.

William Oakes, Service-Learning in Engineering: A Resource Guidebook, (West- Lafayette, IN: Purdue University, 2002).

Servicelearning.org, What is Service-Learning?, 2008. Retrieved October 19, 2008, from http://www.servicelearning.org/what is service-learning/index.php

Michael Thompson, William Oakes, George Bodner, "A Qualitative Investigation of a First-Year Engineering Service Program," Proceedings of the American Society for Engineering Education Annual Conference, 2005, 1-16.

UC Merced - Foster Family Center for Engineering Service Learning, Service Learning Overview. 2008. Retrieved October 19, 2008 from https://eng.ucmerced.edu/slp/portal/overview-1 